\title{
Making University Campuses Suitable for the Physical and Motor Disabled People (Case Study: College of Fine Arts, University of Tehran)
}

\author{
MATIN BASTANFARD ${ }^{1}$ and KATAYOUN TAGHIZADEH ${ }^{2}$ \\ ${ }^{1}$ Holder of a Master's Degree in Architecture, Faculty Member of Shahrood University of Technology, \\ ${ }^{2}$ Holder of a PhD Degree in Architecture, \\ Associate Professor of School of Architecture, University of Tehran. \\ http://dx.doi.org/10.12944/CWE.11.Special-Issue1.09
}

(Received: July, 2016; Accepted: August, 2016)

\begin{abstract}
Social growth and prosperity in any society depends to a high extent to supply of welfare facilties and providing suitable spaces to use them. These facilities assist in the grounds for social growth only if their scope covers all individuals of the society with special needs. Since a major part of any society is constituted by the aged, disabled, impaired and disabled people, failure to pay attention to that class not only may result in their lack of motivation and deprivation of society from the capabilities of such an important class, but also it may impose heavy social and economic costs on the country. Therefore, equalization of opportunities in enjoying social facilities is of great importance for that class. An approximately $10 \%$ disability estimated by the international community for Iran with a population of over 70 million people based on the general census in 2006 can include approximately 7 million disabled with different kinds of disability. Architectural and urban obstacles are among those major problems for the physically disabled people that hinder them from attending in social, economic and cultural activities. The existing problems in urban pedestrian access network and lack of any continuous easy movement in walking routes, staircase in many buildings and lack any elevator between the building storeys have made impossible independent movement in the city and use of buildings for a part of the society. In this way, College of Fine Arts of the University of Tehran as one of the university spaces with a long antiquity and at the same time with access problems for physical and motor disabled people has been studied so that some solutions can be provided for the disable to improve the spaces of that college.
\end{abstract}

Keywords: Disabled, Making Suitable, University, Architecture

\section{INTRODUCTION}

One of the principles accepted by the philosophers is the principle of movement. They believe that the world is thoroughly in the course of movement and movement in human includes gradual change and development of any creature to improve the forces stored in it to excellence. Therefore, necessary facilities for evolution and improvement should be available for all classes of the society.
Disabled people are not an exclusion to this rule. Their existence among other classes of the society, their participation in social activities and use of facilities that other people enjoy them as well can not only serve as a factor for development of the disabled people and their overcome to their physical and mental problems and difficulties, but also can result in the community's use of such group of human force. The goal of this study is to understand the problems of physical and motor disabled people throughout the 
universities and especially the College of Fine Arts of the University of Tehran. It should be noted that considering the available fields in the College of Fine Arts and student admission in those fields and also considering the fact that physical and motor disabled individuals are more likely to be admitted in those fields, pathology and solutions have been provided for those individuals as detailed in the paper so that they can serve as an example for planning for similar cases.

\section{Disabled and disability}

Disability is a kind of physical or mental inability that faces an individual with several problems in supplying the life necessities. A disabled person is not naturally able to perform his/ her routine activities and needs to use special aids and assistance of other individuals. On this basis, disability can be defined as "A complication caused due to weakness or disorder in sensory, nervous and motor system resulting in disordered movement and communication of a person with the environment".

\section{Definitions of World Health Organization (WHO)}

Disorder 1: Any loss or abnormality in mental, physical or organ structure or function. Disability or disablement includes any restriction or loss of ability to perform an action in the manner that it has been recognized as common form human.

Disability 2: A description taken from disorder or disability hindering the individual from performing a role which is considered natural. According to the definition of disabled people international organization center (DPI), disability is the loss of or restriction in the possibility of partnership with other people in the common social life.

\section{Statistics of disability in the world}

The statistics issued in the recent years by statistical centers in different countries of the world indicate the reality that the number of disabled people in the developing counries is still increasing due to shortcoming of health services as well as problems arising from accidents in the workplace and that at least one child among ten children is disabled.
National and international rules for supporting the rights of the disordered

Article 2 of the comprehensive Law for supporting the rights of the disabled

When designing, producing and constructing buildings and public places, passageways and service tools, All ministries, public organizations, institutes and companies, public and revolutionary institutions are obligated to act such that the possibility of accessing and enjoying the said facilities are provided for the disabled the same as for the ordinary people.

\section{Article 3 of the international convention of the disabled people's rights}

Article 9: In order to enable the disabled to live independently and to fully participate in all aspects of life, member states will adopt appropriate measures to ensure the access of the disabled equal to other people to physical, transportation, information and communication environments including information and communication system and technology and other facilities and services provided for the public in the urban and rural regions.

\section{Different types of disability \\ Disability is divided into three classes. \\ - Mental disability or retardation \\ - $\quad$ Physical disability \\ - $\quad$ Social disability}

\section{Mental disability or retardation}

Mental retardation is the failure of mental activities of an individual in the manner that he/she cannot adapt to social and economic environments and necessary skills expected from him/her relative to his/her peers. This group of the disabled that are mentally in trouble are called mentally disabled people and are divided into three groups:

- Educable (Kana): This group are able to attract a few of educational subjects up to elementary level and to learn professional education.

- Educable (Kaliv): This group is able to understand simple concepts and they usually perform simple personal tasks.

Deep (isolated, shelter): This group is not able to perceive any kind of education. 


\section{Physical disability}

The physically disabled who suffer from disability or total inability of the activities of their body organs are divided into two groups of the sensory disabled and sensorimotor disabled.

\section{The Sensory Disabled}

Vision and hearing disabilities are among the sensory defects. A Designer should take additional information resources and systems or substitutes for those suffering from such inabilities.

Dimensions, standards and equipment required by the disabled individual

\section{Anthropometric features (Anthropometric} dimensions)

When specifying basic needs for designing a system especially in consideration of human activities, physical dimensions of human's body should be absolutely addressed, especially that this system is the motor system of an individual in urban spaces. Therefore, the basic needs of an ordinary individual is identified first and then, dimensions and sizes of the disabled are dealt with.

\section{Dimensions and sizes of the disabled}

In the first step, the main thing is to specify that for which people and for what purpose university spaces should be made appropriate. In the morphology of disability and the disabled, addressing the dimensions specific to the disabled as well as motor restrictions of those people allow the establishment of spaces in which the disabled travel easily. In other words, functional aspects of different spaces are studied by considering these criteria. Due to motor restrictions of the disabled which include main data in planning for architectural spaces, certain criteria and dimensions are presented for the disabled that ensure motor facilities and their accesses. The highest motor problem refers to those disabled who use wheelchairs. Thus, it is necessary to review dimensional standards for the said vehicle.

Figure 1) Classification of the disabled in view of urban planning and architectural design Right to left:

- Classification of the disabled in view of urban planning and architectural design

- $\quad$ Semi-mobile disabled (standing)

- $\quad$ The disabled on the wheelchairs (sitting)

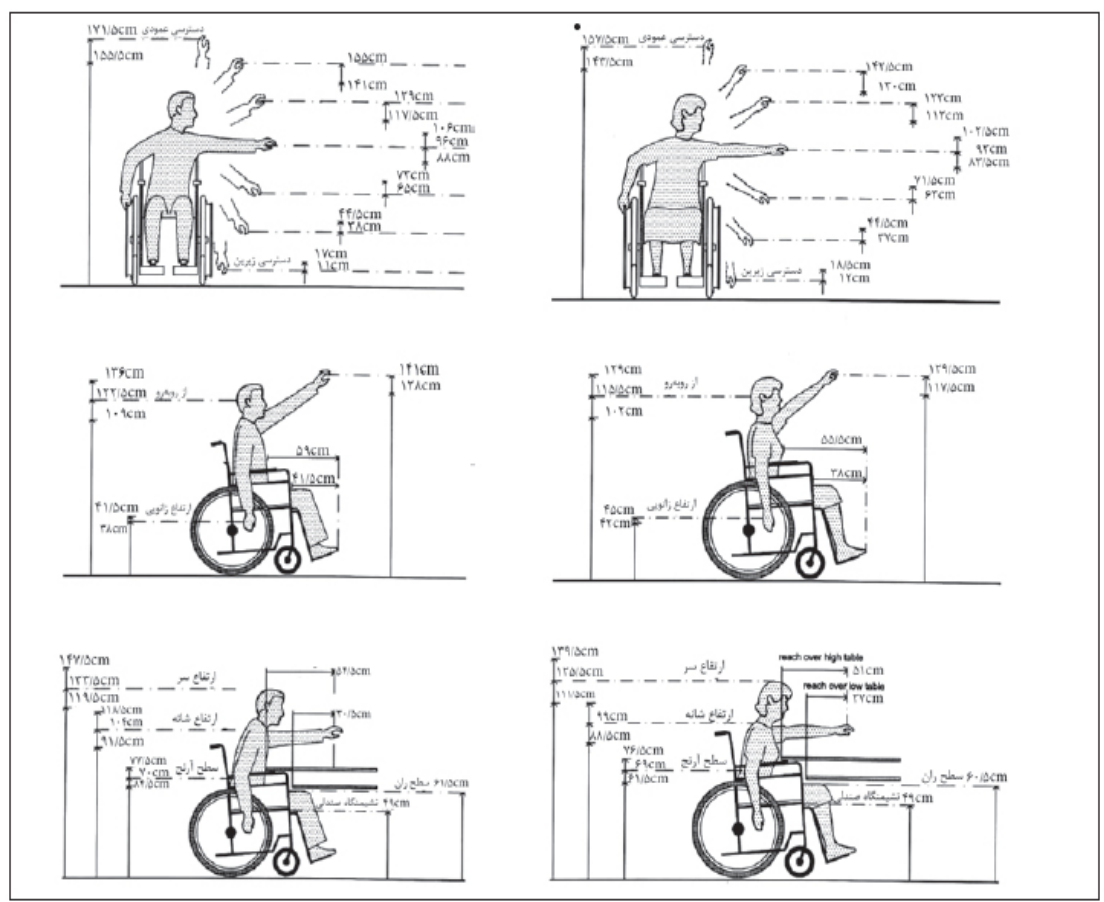

Fig. 2: Dimensions and sizes of vertical and horizontal accesses of wheelchairs 
- $\quad$ Semi-mobile using a stick

- $\quad$ Semi-mobile using artificial organs

- $\quad$ Single-stick

- Double-stick

\section{Wheelchairs}

In fact, a wheelchair is the most troublesome aid in view of volume, weight and space occupation. On the whole, whenever space and obstacle-free distances are design in such a way that they can be used by wheelchairs, the said space can be also usable both by the individuals who take advantages of other motor aids and by normal people. Due to the most limitation from among common motor aid equipment, wheelchairs are considered as base.
It building limitations and volume of chairs are considered, the disabled sitting on wheelchairs can do different tasks like a person who is capable of doing any movement. Under any condition, due to impairment, these individuals can approach vehicles and use them only through a path of certain dimensions and in a specific position.

\section{Stick, crutch and walker}

The facilities that are available in places considered for the disabled sitting on wheelchairs, can be also used by the individuals who use stick, crutch and walker. All motor aids cause the user to need a space a bit larger than that required by the ordinary people. Those who use stick and crutch

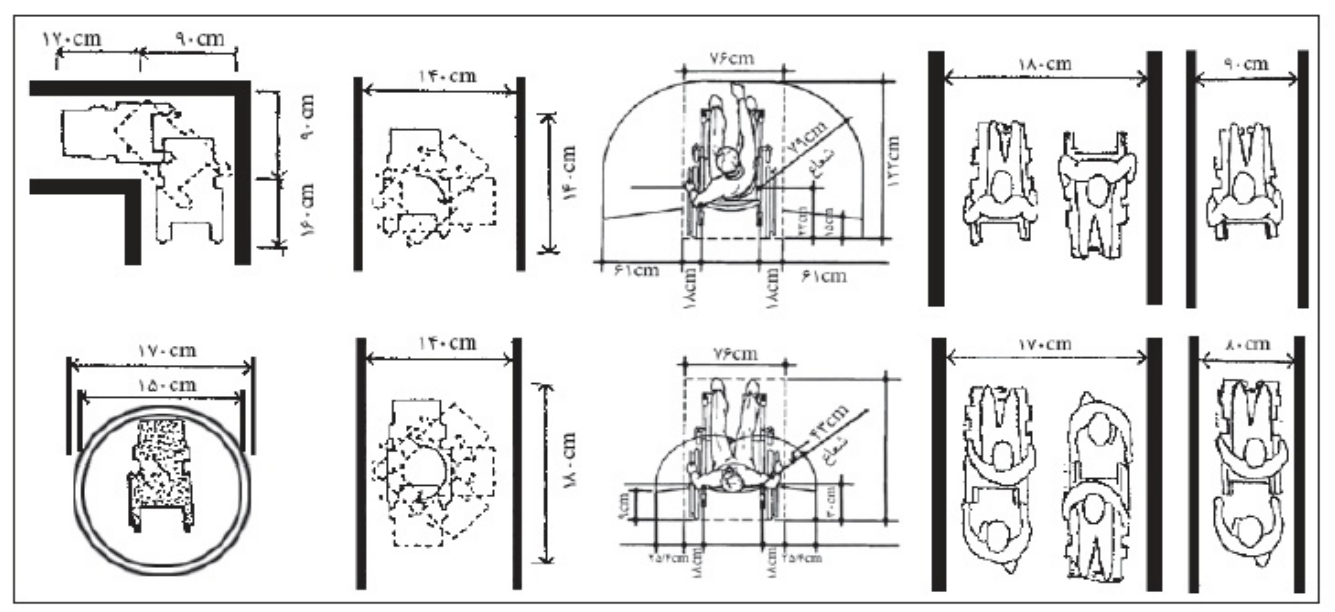

Fig. 3: The maneuverer of wheelchairs in different spaces

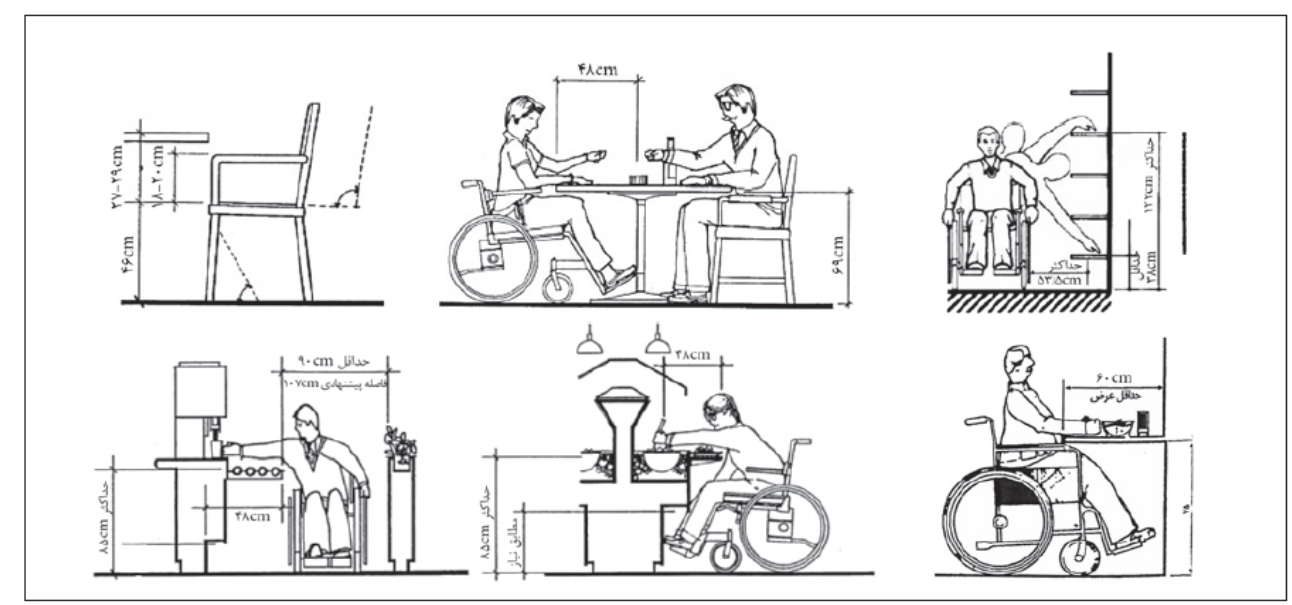

Fig. 4: The space required by wheelchairs in public spaces 
are able to adapt themselves with spatial conditions especially if the distances are short. The space intended for the disabled on wheelchair is enough for the person who use a walker although this person is not able to adapt himself with spatial conditions.

The societies which are successful in the rehabilitation of the disabled, while dealing with therapeutic-training and professional stages for these people, had considerable studies and researches in the field of urban and residential design and planning for the disabled by considering their special physical status. Nowadays, all public cities and buildings have become appropriate in the said societies. Rehabilitation experiences in the world have proved that rehabilitation and access of the disabled to independence in individual and social life will be impossible without environmental adaptation.

\section{Urban problems and impediments for the disabled}

As it was said, one of the major problems for the disabled is the lack of attendance in different urban fields. Therefore, capabilities and dimensions of the disabled should be addressed in designing all urban and public spaces including universities and other educational spaces. Moreover, obstacle-free spaces should be established so that movement restrictions casused by surface difference, rough surfaces, short width of passageways and other restrictions are removed and urban evironments can be usable for all physical and motor disabled. By studying physical needs of physical disabled and the process for making the environment suitable for that group, it is concluded that the said group sometimes face problems due to use of wheelchair and other aids as well as larger spaces. A group of these problems is related to the obstacles in public places including unlevelled surfaces, etc. and the other group is related to non-harmony of passageways and equipment with the standards of the disabled individual who uses a wheelchair.

The restrictions of the disabled individual who uses a wheelchair are as follows.
a) $\mathrm{He} / \mathrm{she}$ is in a surface lower than other people (height restriction)
b) They are wider than other people (restriction in width)

c) They can go only to the places where it is possible for the wheelchair (restriction in movement and passing from unlevelled surfaces).

\section{Regulations and recommendations for suitable- building}

Activities and measures that allow the movement of the disabled in the urban space can be reviewed and studied from two aspects. First, design of new spaces suitable for movement of the disabled and second, making the existing spaces suitable which is coupled with some changes in the skeletal structure of city and buildings. In this regard, functions which are important in the routine life of the disabled are made suitable. Based on the existing experiences, suitable-building in the developed industrial countries is mainly reviewed in three general fields which are as follows:

a) Exterior spaces of building;

b) Access spaces to the building;

c) Constructed spaces.

Regulations and recommendations for suitable-building of exterior spaces of the building (area) Passageway network of the university including pedestrian and riding networks and their interface. Passageway network as a ground for motion of an individual in environment is regarded as the most important element in making university campus suitable and in fact, it provides the facilities required for motion in environment.

\section{Existing sidewalks}

One of the most important issues that should be considered for the disabled in the pedestrian network is the supply of continuous movement and non-stop of pedestrian movement. The second point is the suitable width of sidewalk for the movement of the disabled individual that uses a wheelchair. The other point is to reduce surface difference in the sidewalks. Therefore, high surface difference should be removed in all movement routes because high surface difference disturbs the balance and constant movement of the disabled and they will not be able to pass by a wheelchair.

\section{Standards for suitable-building of furniture in the university area \\ Furniture of the university area includes}


telephone booths, potable water stations, trash bins, benches and utility poles. Suitable-building of urban furniture and/or service elements is more meaningful with respect to offering welfare services, supply of security and comfort and producing suitable factilities for the moving disabled individual and in direct relation with suitable-making of urban elements.

\section{Entrance space or entrance building}

A space by passing through which an individual enters inside a building. Placement of this space in the building design is of a great importance and it is required that it has been correctly designed. In this condition, a normal and organized condition is given to the other parts of the building. Undoubtedly, an unknown entrance will confuse the person who has referred to the building.

Entrance space of a public building should be accessible for all people. However, most of the public buildings are not accessible for the physical and motor disabled who constitute a part of our society due to different obstacles on the entrance way. The existing obstacles on the way of physically disabled people to the public buildings should not be solved by providing sub-entrance ways, but they should be removed by suitable-building of one of the main entrance ways for the disabled. For example, providing a service entrance gate for the disabled makes them think that they are low-important citizens.

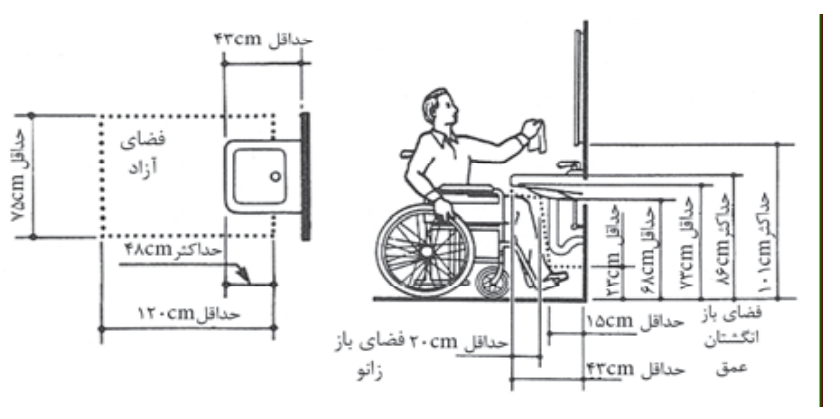

Fig. 5: The required space for the disabled to drink water

Table 1: Standards for designing the ramps:

\begin{tabular}{lll}
\hline Topic & Subtopic & Standards \\
\hline Ramps & Width & Minimum width of ramp should be $120 \mathrm{~cm}$. \\
& Length, ramp and width & Regarding the ramps up to $3 \mathrm{~m}$ in length should be maximum \\
& $8 \%$ of $120 \mathrm{~cm}$ in width. \\
& Oppropriateness & On ramps over $3 \mathrm{~m}$ in length (up to permissible length of $9 \mathrm{~m}$ ), \\
of length, ramp and width & $5 \mathrm{~cm}$ is added to width per $\mathrm{m}$ for increase of length and \\
& $0.5 \%$ of the ramp is decreased. \\
Landing & It is mandatory to predict landing of minimum $120 \mathrm{~cm}$ in depth \\
& per 9 m. On two-direction ramps, the width of landing equals \\
& to that of the ramp. \\
Floor cover & The floor of the ramp should be non-slippery. \\
Cover & The building entrance ramps should be the roof. \\
Stair rail & It is mandatory to install the stair rail on both sides of the ramp. \\
Height of the stair rail & The height of the stair rail from the floor of the ramp should be \\
& $75 \mathrm{~cm}$ for a sitting person, $85 \mathrm{~cm}$ for a standing person \\
& and $60 \mathrm{~cm}$ for children. \\
Dimensions of the stair rail & Maximum diameter of stair rail should be $3.5 \mathrm{~cm}$, minimum \\
& space between that and the wall should be $4 \mathrm{~cm}$.
\end{tabular}




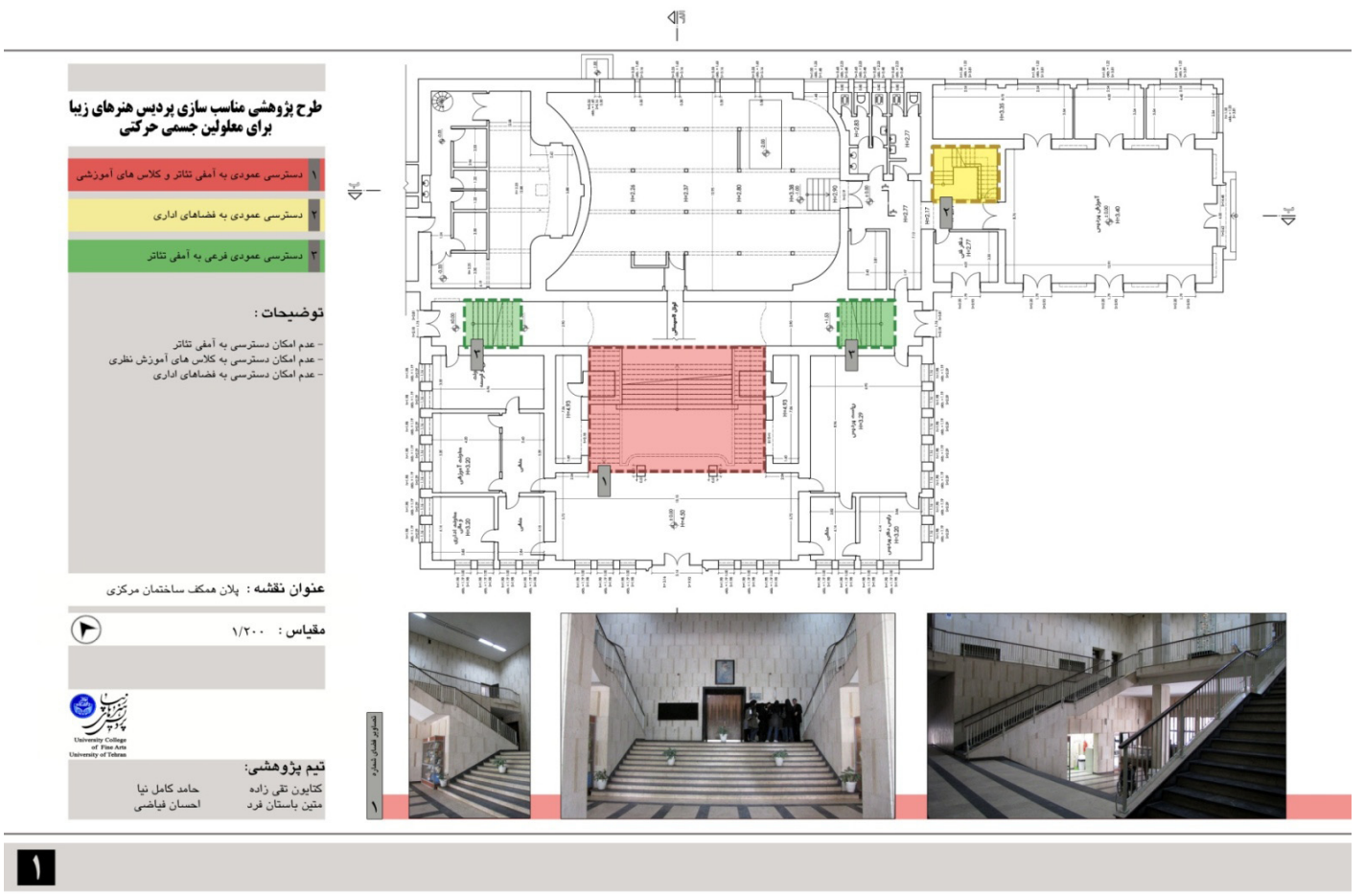

Fig. 6: Studied sections of Faculty of Architecture
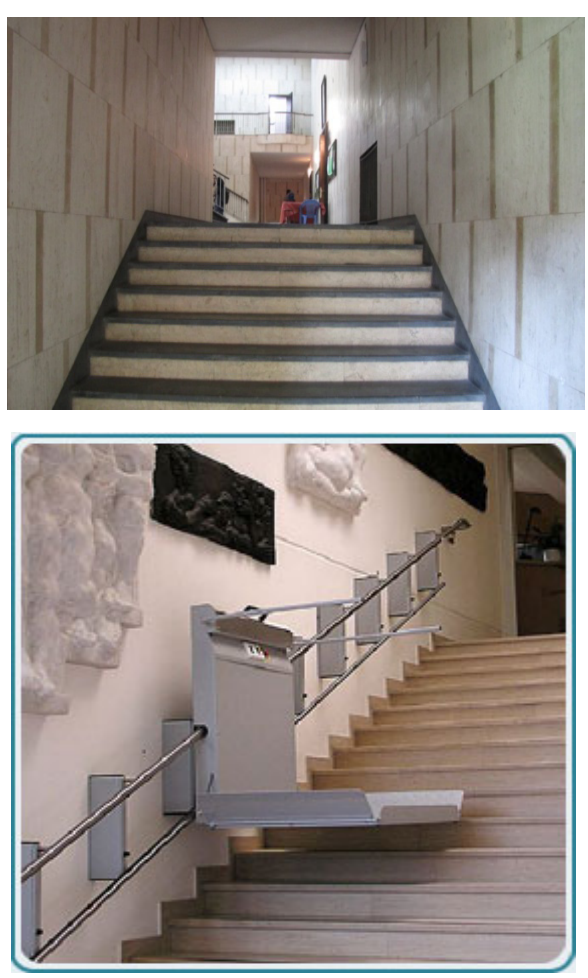

Fig. 7: Proposed solution for a sub-access to the amphitheater
Problems of entrance space for the disabled Entrance stairs

The buildings which may be entered only through stairs are inaccessible for the disabled. Unfortunately, design of stairs in the entrance of the buildings and especially public buildings is quite common and most of the buildings have such obstacles for the access of the disabled. Those disabled who use wheelchairs usually cannot use stairs and basically, stairs are one of the major obstacles on the way of the disabled who use wheelchairs. But physical and motor disabled who use sticks, walker, etc. (no wheelchair) can use stairs for vertical movement. Even when the flooring of a ramp is a slippery flooring, they maybe prefer stairs to the ramp. In such cases, the width of landing plate, stair height, the type of flooring covering the stair as well as height and shape of the rail beside the staircase should have special conditions which will be discussed below.

\section{Low width of landing plate}

When coming down the low-width stairs, people face the risk of falling because their souls are not placed properly on the landing plate. 


\section{Long stairs}

Stairs with a height more than common standard put an individual into risk due to the height difference caused between his/her two legs.

\section{Stairs with round edges}

A person who intends to come down such stairs often face problems in his/her movement. If this disabled person uses aids, it is likely that the round edge of the stairs disturbs his/her balance and causes his/her fall. In such cases, the risk of fall is more likely of the aged.

\section{Useless Stair Rail}

Stair rails on one side or both sides of the stairs help disabled people with movement problems. If the height of stair rails is shorter than hand of individuals or they cannot be grasped by the individuals due to their form, they are useless for the pedestrians.

\section{Non-passable path between the car park and building entrance}

The disabled referring to public building using private vehicles, need to park their car at the nearest parking lot. If the distance between the car park and the building entrance is too long or there is a non-passable street between the parking car and the building, it is actually impossible for the disable to enter the building.

\section{Short distance between the two entrances}

In some buildings, after the main entrance door, there is a little room as entrance space and connects this space to the interior area in other one. In cases where there is not sufficient space between the two entrances, after arriving through the main door, the disabled should immediately open the next door before the main door is closed. Such design mostly prevent the disable accessing the interior area due to passage problems.

\section{Recommendations for design and making the entrance suitable}

- At least one entrance should be intended at public buildings for the disabled.

- A suitable entrance with an access of the street or parking of building is necessary for the disabled.

- No obstacle should exist on the sidewalk leading to the entrance for the disabled.

The surface of the sidewalk leading to the entrance for the disabled should not be slippery.

- $\quad$ Access of building should be at the same level as that of the sidewalk as much as possible. In case of difference in height, access of building is possible with the ramp (the respective particulars should be given in the related section).

- A shed of at least $140 \mathrm{~cm}$ in width is recommended in front of the entrance.

- The height of the threshhold should be at least $2.5 \mathrm{~cm}$ in height to prevent rainwater. If the threshhold is of about $5 \mathrm{~cm}$ in height, it should be connected to the floor with ramp on both sides.

\section{Design standards and making the accesses appropriate}

According to the principles and standards of architectural design of general buildings ratified by the Supreme Council of Urban Planning and Architecture of Iran, access elements of a building should have the following characteristics:

\section{Entrances}

- The entrance door should be accessible by public.

- $\quad$ The entrance of building should be at the same level as that of the sidewalk.

- The least depth of front area of the entrance should be $140 \mathrm{~cm}$.

- $\quad$ The least sash width of the building should be $100 \mathrm{~cm}$.

- $\quad$ The accessible entrances should be connected to public station vehicles, accessible parking lot and rides of passengers, public streets and sidewalks through an accessible road.

- $\quad$ The entrances, making an accessible road to all accessible elements and spaces inside the building should be connected to the facilities.

\section{Sashes}

- The least useful width of each slide should be $80 \mathrm{~cm}$ at least for passage of wheelchair. For the doors that open to the public passage, it is mandatory to provide sufficient sight. Under any condition, the projection of slide 

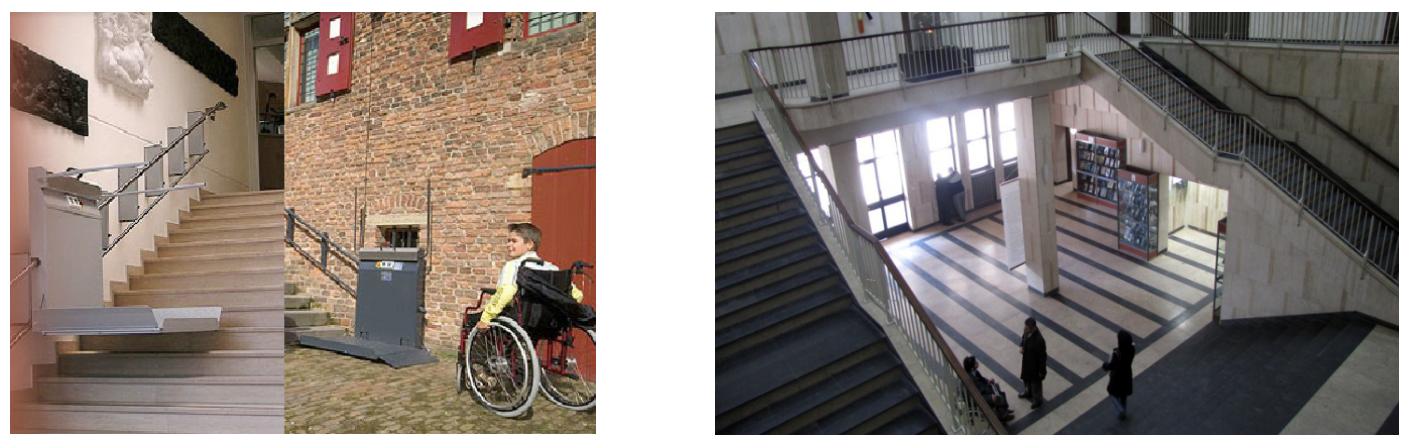

Fig. 8: The proposed solution for vertical access to amphitheater and classrooms
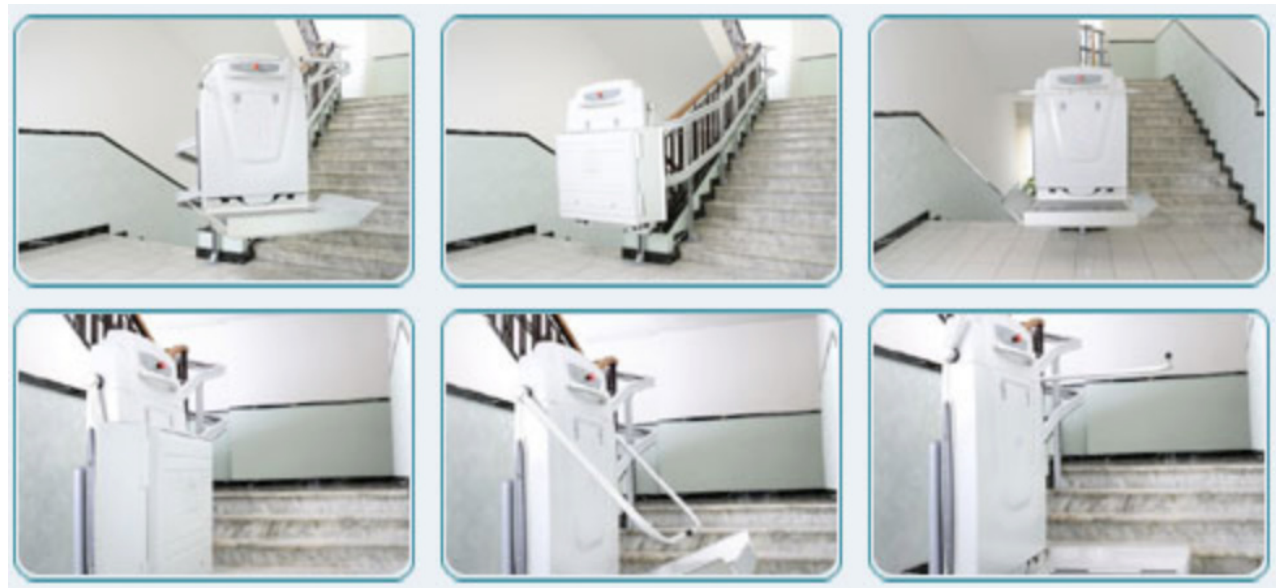

Fig. 9: Function of Stair Wheelchair Carrier of turning type
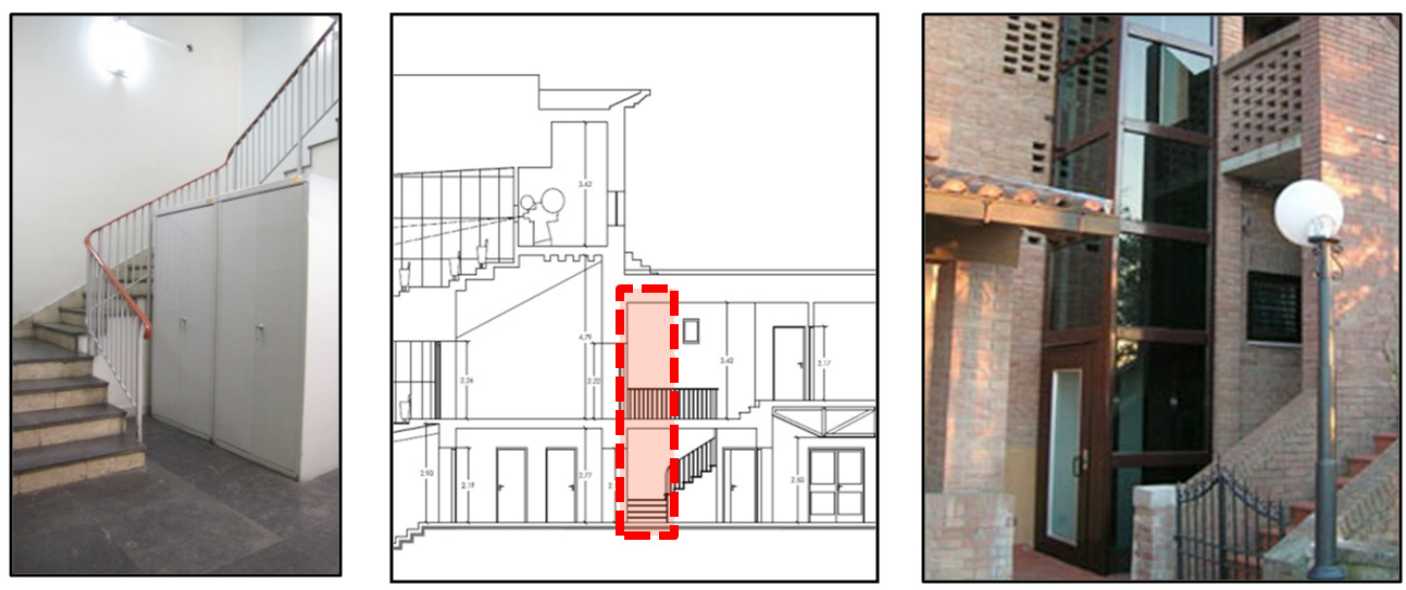

Fig. 10: The proposed solution for vertical access of office spaces 
opened on the public road should not exceed $10 \mathrm{~cm}$.

- Doors should have kickers of $25 \mathrm{~cm}$ in height.

- In case of use of turning and sliding doors that are not usable by the disabled, it is mandatory to predict an ordinary door with at least 80 $\mathrm{cm}$ as useful width in the vicinity of the said doors to be used by the disabled.

- $\quad$ All doors should be easily opened and

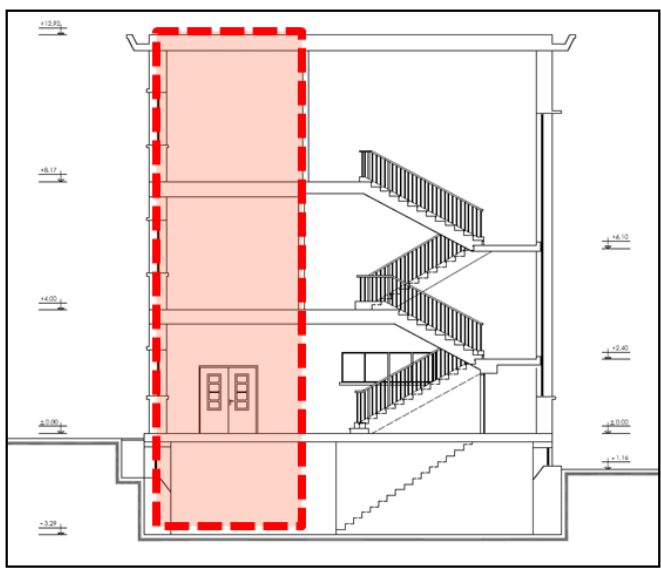

Fig. 11: Proposed solution for vertical access to architectural ateliers No. 1 and 2

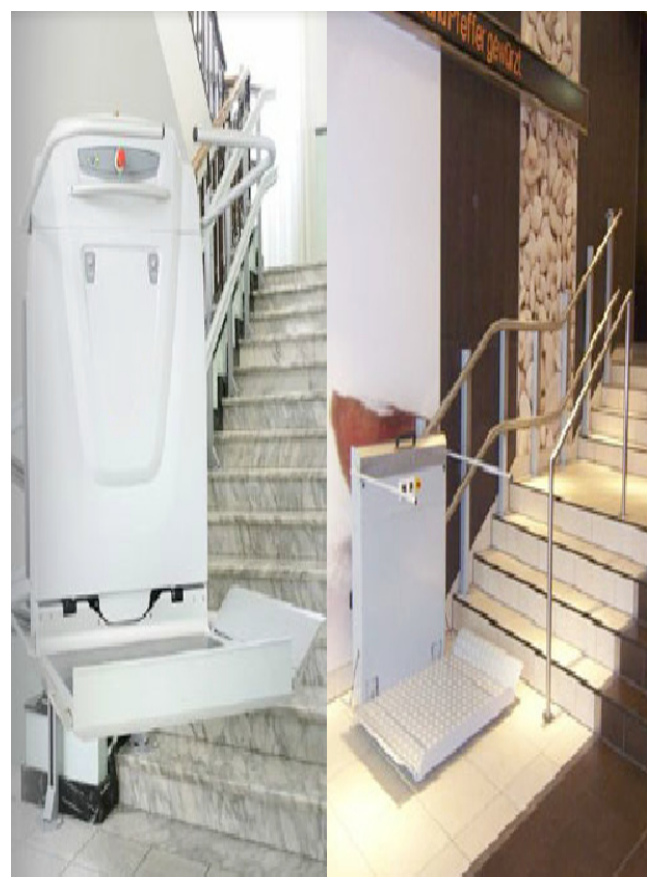

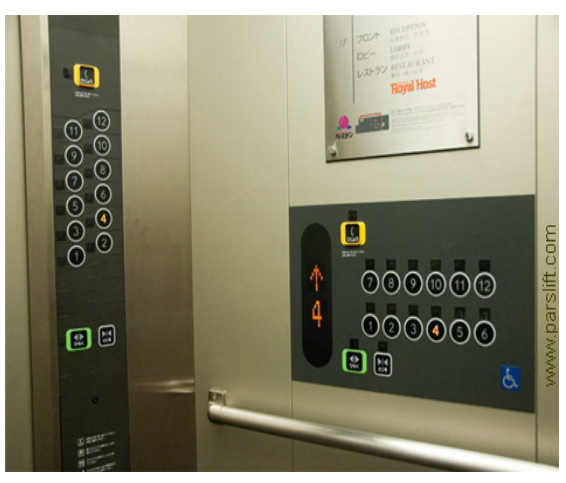

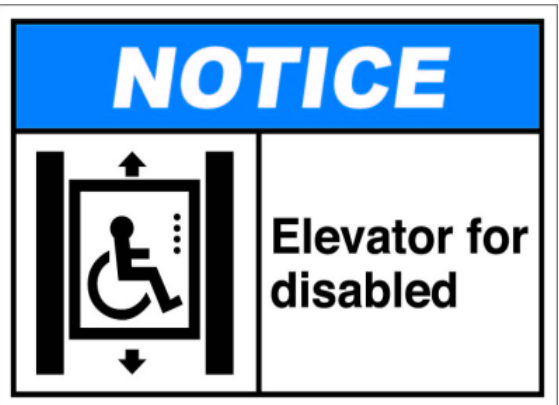

Fig. 12: The notice of Elevator for the Disabled
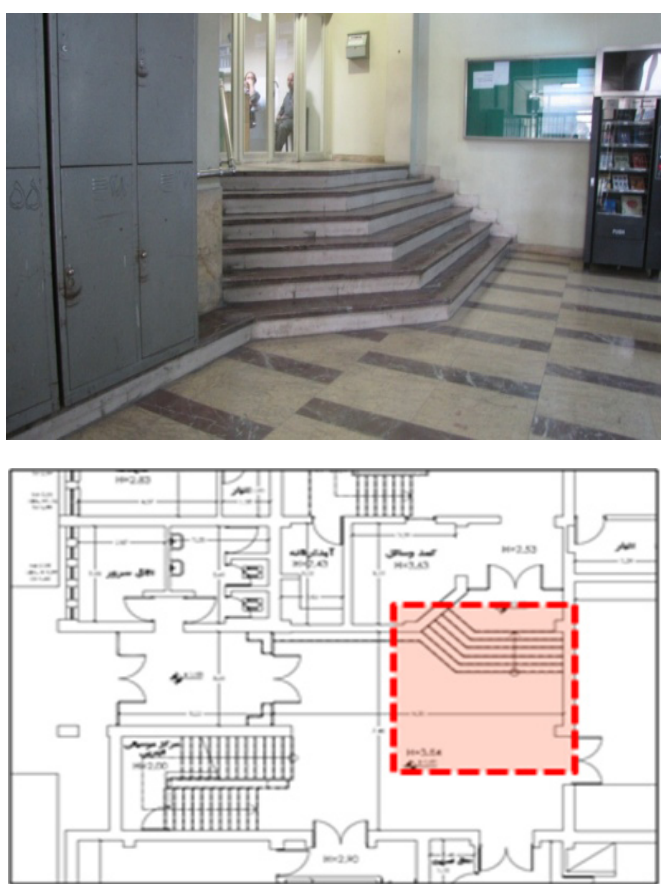

Fig. 13: Proposed solution for access of library 
closed.

- Door handles should be of lever type and their color should be different from the door. The internal space between the door and its surface should be $3.5-7 \mathrm{~cm}$.

- Minimum space between two consecutive doors if both open in one direction, should be $280 \mathrm{~cm}$.

- $\quad$ The doors should have at least no threshold. Where necessary, the height of the threshold should be $2 \mathrm{~cm}$.

- To facilitate movement, it is mandatory to predict a surface at the same level of that both sides.

- Emergency exit should be accessible and
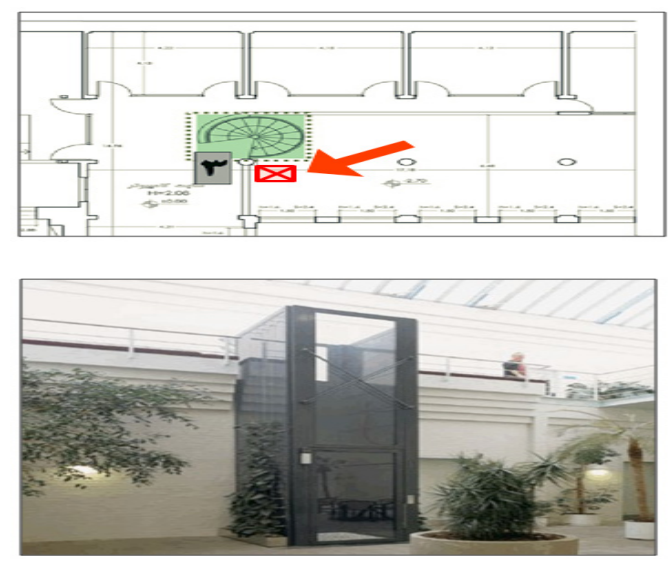

Fig. 14: suitbale place to devise the elevator in the site
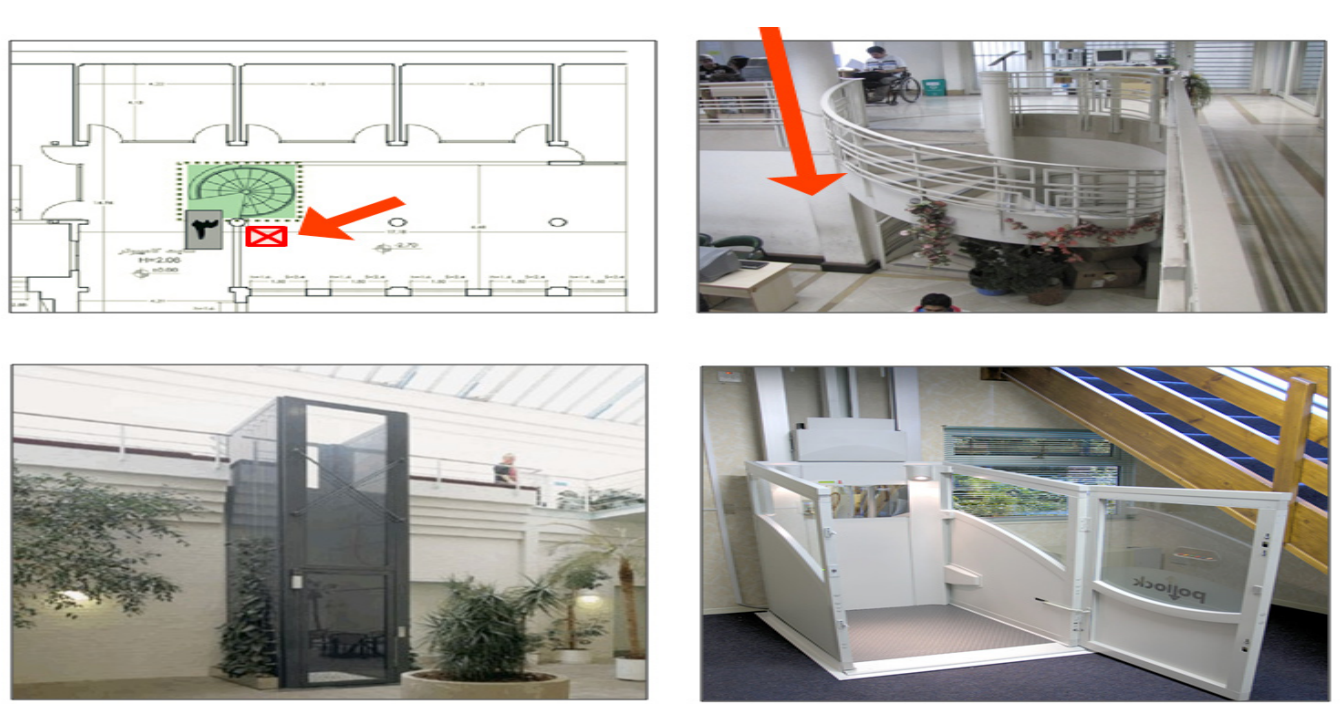

Fig. 15: Proposing the use of elevator to carry the wheelchair in the site

at the same level, and should end in an accessible direction.

The height of door handle from the bottom should be $10 \mathrm{~cm}$ at the most. bar (rail) on the doors.

All doors and windows with glass down to the bottom should be protected against impulse.

- $\quad$ The sash angle of door should be minimum 90 degrees.

\section{Stairs}

- $\quad$ The width of landing plate should be $30 \mathrm{~cm}$ and its maximum height should be $17 \mathrm{~cm}$. The minimum stair width should be $120 \mathrm{~cm}$.
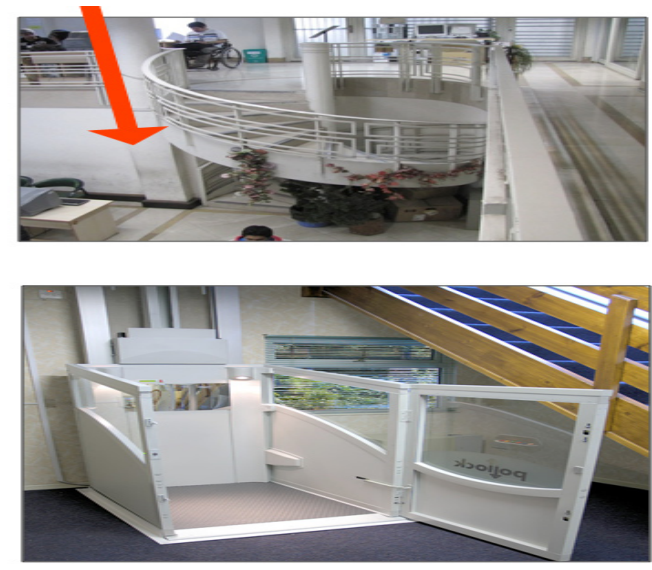
- It is mandatory to install rails on both sides of stairs.

- The stairs should be of hard and non-slippery materials.

- $\quad$ The edge of the landing plate should have a maximum round radius of $13 \mathrm{~mm}$.

- $\quad$ Annexing any unleveled parts on the landing plate is forbidden.
Maximum number of stairs between the two landings should be 12 steps.

Minimum dimensions of stair landing should be $120 \times 120 \mathrm{~cm}$.

\section{Ramp}

Recommended solutions

Considering the previous discussions, it
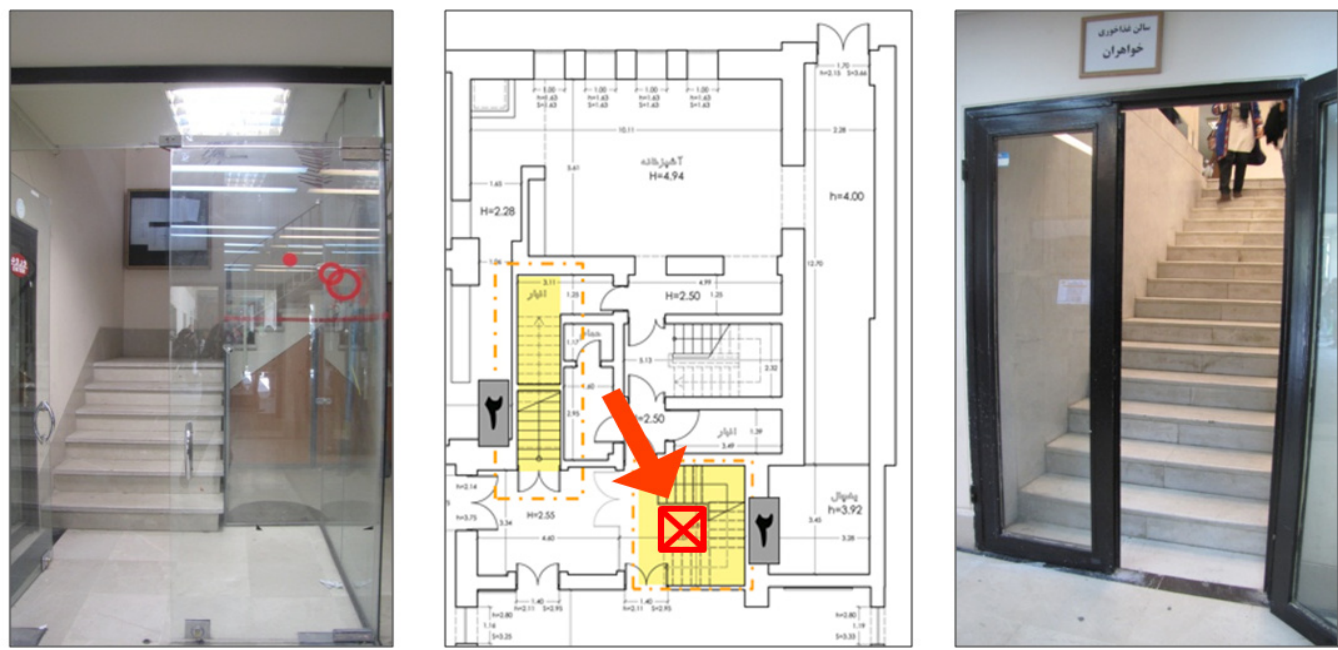

Fig. 16: Current status of connection with women's dining hall and students' affairs deputy office
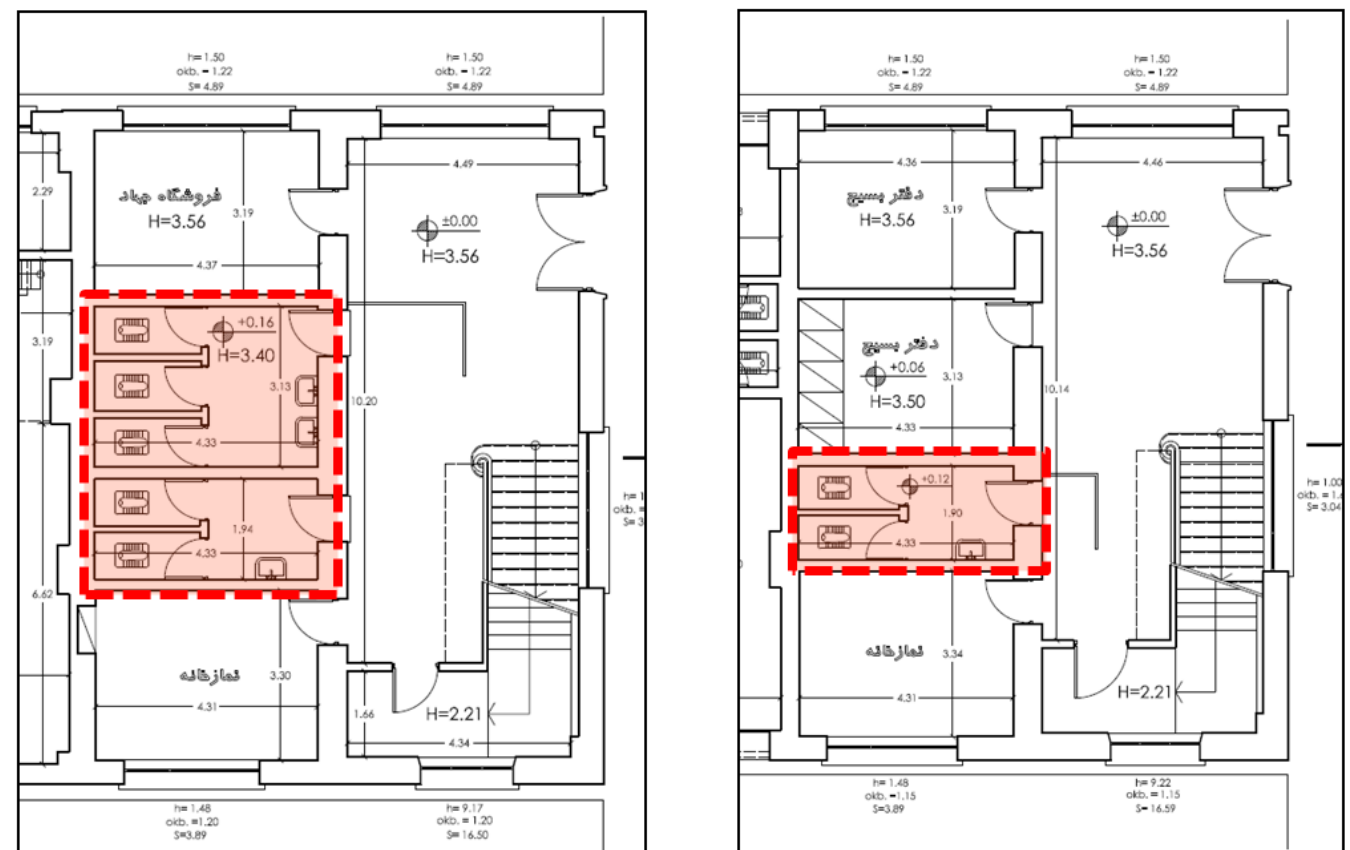

Fig. 17: Current condition and layout of santiary services 
is found that due to several reasons the college of fine arts have basic problems and restrictions with respect to access and the possibility of movement for the physical and motor disabled people. At any stage, these problems cause an obstacle in independent movement of a person in different sections. Therefore, some solutions may be achieved by classification of the said problems.

Providing a connection between access networks and buildings

- The existing obstacles on the sidewalks should be omitted to prevent from transfer of pedestrians from sidewalk to the roadway.

- All holes and depressions caused by different reasons on the sidewalks should be repaired.

- $\quad$ Bridges should be installed on the waterways to differentiate between sidewalks and roadways. Precise construction and consuming materials in these types of bridges usable by the disabled are effective.

- Regulations should be approved to prevent from parking of cars on the width of the sidewalk in front of the box aqueduct and pavements so that they do not impede passage of people.

- In order for the disabled to use telephone booths, they should be installed at an appropriate height suitable for the disabled.

- $\quad$ Since it is difficult for the disabled to travel on long distances under sun, rain and snow, sunshades should be devised on proper places to protect the said people under climate conditions.

Pathology maps and the recommended solutions for different parts of the college of fine arts are presented hereunder.

Recommendation for lateral accesses to amphitheater (Space No. 3):

As the use of a ramp is not possible due to lack of the required length, use of wheelchair on a straight stair is an acceptable option. This vehicle is recommended to transfer the disabled and aged as well as those who use wheelchairs at the places where no elevator or ramp can be devised.

The lower plate of the vehicle is automatically folded and occupies less space when the vehicle is not used. Consuming energy of the system is supplied by two $12 \mathrm{~V}$ batteries and eventually it will work upon power disconnection. This model is suitable for straight staircases with no arch, turn or landing.

The advantages of the aforesaid system are as follows:

- $\quad$ Suitable for the patients, disabled, etc.

- Use of power and battery even upon power outage

- Capable of being installed on right or left side

- Designed and produced according to the latest the European Quality Standards

- $\quad$ Foldable when it is not used to occupy less space

- $\quad$ Easy and quick installation without any need to destruction or change of stairs

- Two certifications of European Safety Standard

- $\quad$ Equipped with five obstacle detecting sensors

- Low noise

- Easy control by joystick and remote control

Recommendation for vertical access to amphitheater and classrooms (Space No. 1)

- $\quad$ As the use of a ramp is not possible due to lack of the required length, use of wheelchair on a straight stair is an acceptable option. This vehicle is recommended to transfer the disabled and aged as well as those who use wheelchairs at the places where no elevator or ramp can be devised.

- The lower plate of the vehicle is automatically folded and occupies less space when the vehicle is not used. Consuming energy of the system is supplied by two $12 \mathrm{~V}$ batteries and eventually it will work upon power disconnection. This model is suitable for straight staircases with no arch, turn or landing.

- This model is capable of turning on landings and rotation in curved or circular steps.

This system has several advantages similar to the wheelchairs used for the straight stairs already mentioned above. 
The function of stair wheelchair conveyor has been shown in the following images. This option is discussed as one of the main choices for suitablebuilding in central buildings of college of fine arts considering minimum damage, interference and occupation of minimum space

\section{Recommendation for vertical access to office sapaces (space No .2)}

Space at office section of the central building is a suitable place to device the elevator. An household hyraulic elevator is a suitable choise for this purpose.

There is no need for destruction or a large space to install this elevator. In displacement systems, hydraulic climbing jacks are used which

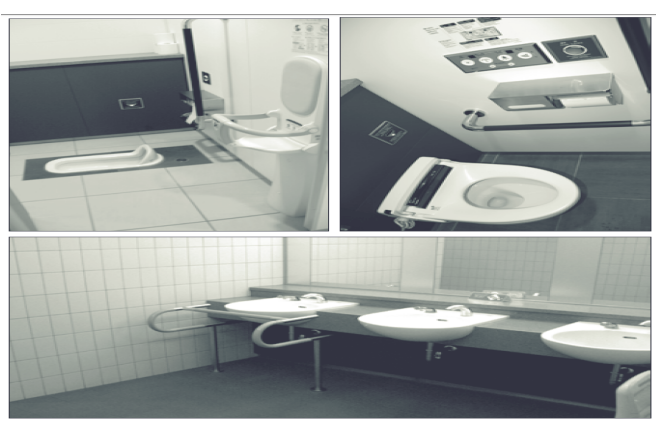

are placed inside the elevator cabin. As a result, in addition to the minimum required space, no pit, mechanical room, wire rope and weight. It works with single-phase urban electricity. This type of elevator is capable of lifting $300 \mathrm{~kg}$ and it can be installed in places where it is not possible to install ordinary elevators such as inside the staircases (like the exiting sample), corridors, shops, yards or overpasses.

A supporting system for landing and exiting people upon power disconnection is among other advantages of these elevators over similar systems.

\section{Solution for vertical access of architectural ateliers No. 1 and 2}

Entrance space adjacent to drop box

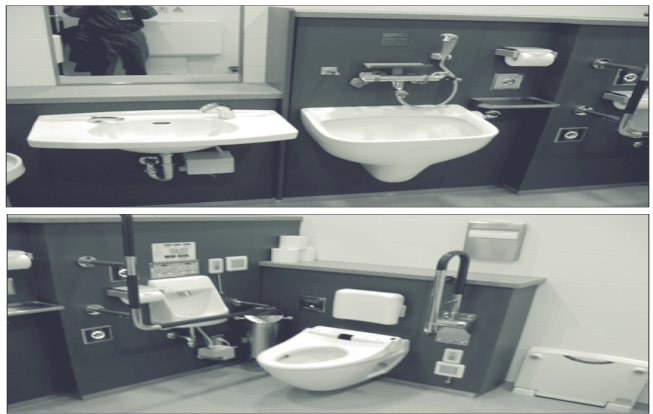

Fig. 18: Suitable layout of sanitary service for the disabled
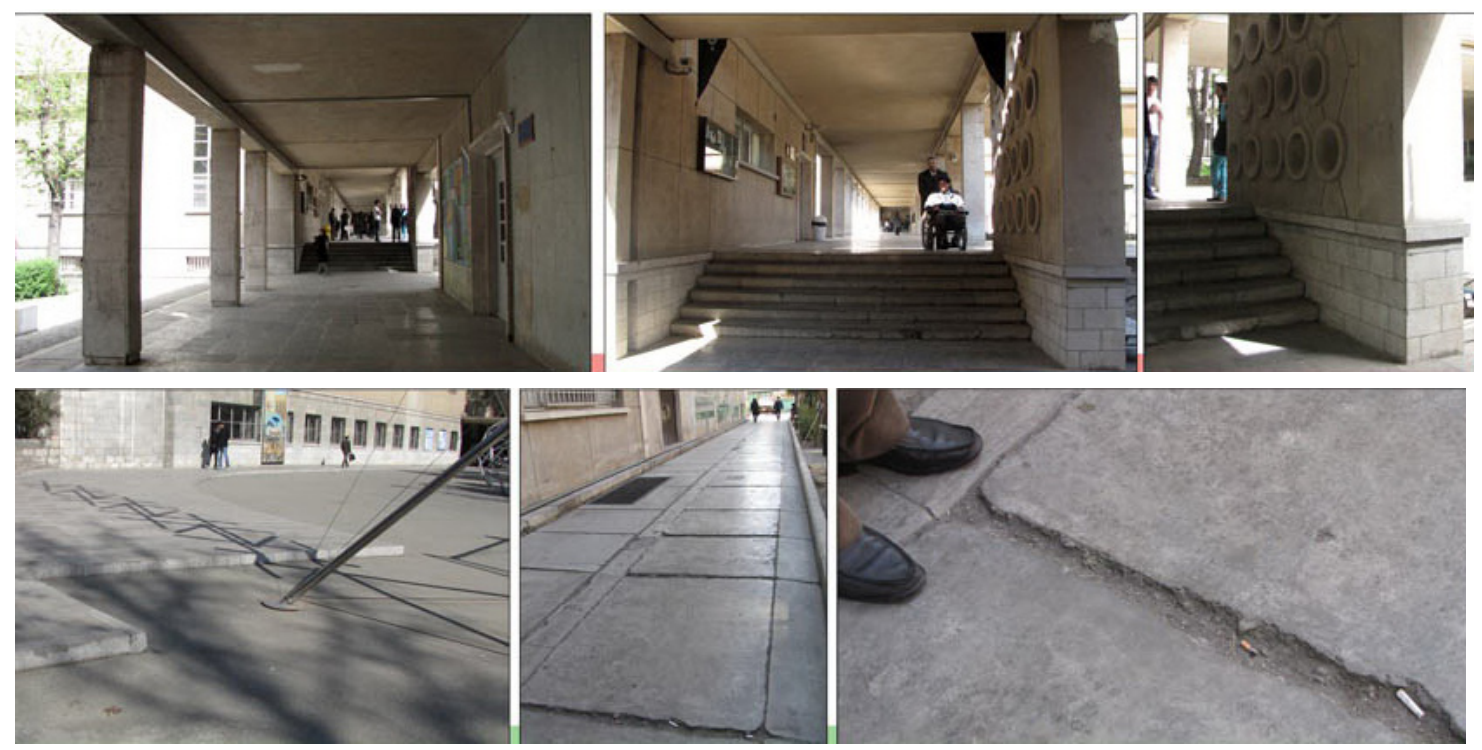

Fig. 19: Images of current condition of the campus of College of Fine Arts 
shown in the image is a suitable place to devise the elevator although devising the elevator in this space necessitates certain changes in the functions of upper floors within this limit. Proposed limit to devise the elevator is given in a section of the building of the existing ateliers.

Layout of the precise location of the elevator, if this solution is accepted as top choice, more precise studies should be conducted that is reviewed at executive phase of the research.

Another option is to choose step wheelchair carrier of turning type of which advantages have been given earlier.

\section{Solution for vertical access to architectural ateliers No. 1 and 2}

The situation of this space is similar to that of building of ateliers No. 1 and 2 and the same two options of either devising an elevator or use of a step wheelchair carrier of turning type is put forth.

Following particulars should be taken into consideration about the useful elevator for the disabled:

- $\quad$ Equipped with a sliding door with an electronic eye

- Useful dimensions of the elevator enclosure at $140 \mathrm{~cm}$

- It is mandatory to devise aid handles on the walls of elvator at $85 \mathrm{~cm}$ in from the bottom of the enclousre.

- $\quad$ The heightof elevator controlling bottons should be maximum $130 \mathrm{~m}$ at highly-travelled places by the disabled.

- It is necessary to specify elevator stop, using a ring.

\section{Solution for access to library}

Use of ramp for access to library is not a helpful option due to impossibility of providing the required length. It is recommended to use a straight step wheelchair carrier for this space.

\section{Proposed solution for access to bottom floor beneath the computer site}

Devising sevral computers on the ground balance has fulfilled the need of the disabled to use the elevator to some extent. But concerning that computer classes are held in bottom floor, it is necessary to connect the said floor to downstair. To solve this problem the place adjacent to the stair rail is the suitable place to devise the elevator for the disabled.

Solution for vertical access to dining room for women and vice presidency for student affairs

Use of straight step wheelchair carrier is the only possible solution for access to dining room for women.

In case this technique is used for transfer of the disabled, the entrance door is omitted or it is constructed in a sliding form so that no interference will be made with the function of the wheelchair carrier.

In order to access the Students' Affairs, a step wheelchair carrier of turning type or a wheelchair can be devised at as shown in the picture.

\section{Reocmmended solutions to facilitate the disabled use of washrooms}

Minimum facilities of fine arts for washrooms of the diabled indicate the necessity to address this issue.

In the pathology section, the lack of any washroom for physical and motor disabled in different parts of college of fine arts was mentioned. It should be noted that the only existing washroom for the disabled in that area is the washroom of professors in the north building of the college.

\section{Washroom of central building}

Ground floor: There is no washroom for students in this floor.

First floor: In this floor, as it is seen in the following image, each floor is located at different level from the floor balance. Considering this item and due to lack of sufficient space to allocate washroom for the disabled, it is proposed that suitable space is allocated for this purpose at the ground floor.

The washroom of the building of architectural ateliers 1 and 2 and building of architectural ateliers No. 3 and 4 
As it is seen in images, at these buildings, no sanitary service has been provided for the disabled. Moreover, the current space is not enough to assign sanitary service for the disabled either. According to the standards of sanitary service for the disabled, it is necessary for these spaces be extended on all sides to provide the required dimensions. The characteristics and standards special for the disabled together with the images of samples of the said space are given hereunder.

\section{Proposed solutions for easy use of the campus of the College by the disabled}

As it is seen in the following images, motion of the physically disabled on the campus of the college suffer from the following problems:

- Impossibility of use of corridor by the physicalmotor disabled to access to different buildings due to surface difference along with the corridor

- $\quad$ Serious damage at the starting point of the ramps of the space that hinder movement of the wheelchair.

- The cracks on campus flooring involves the small wheels of the wheelchair hindering it from free movement.

The following procedures can be used to solve the above problems.

- Use of straight or ramp stair wheelchair carriers to use corridors for the physical and motor disabled in order to access different buildings

- $\quad$ Repairing the starting point of ramps in the area, providing a ramp with a suitable slope in the area

Repairing the flooring of the area.

\section{CONCLUSION}

University campuses is the space for daily life of professors, students and employees and should have the capacity to accept all individuals and provide all related welfare services. Nowadays, lack of infrastructures needed by the physical and motor disabled has hindered their access to university facilities. Disturbed urban spaces and their adaptability with demands and needs of these individuals cause them become isolated. Thus, in fact reorganizing and suitability of these spaces make these individuals back to social life and restart their activity.

In this paper, scientific and practical efforts have been taken to present architectural and instructive solutions for suitability of the college of fine arts as sample so that future architectural students will benefit from campus as a class for practical course.

The main goal of this research was to promote full observance of the principles of suitability at universities and presenting a practical and executive solution. It is hoped that after execution of this research and its comprehensiveness at all universities across the nation, suitable grounds are established to benefit from equal facilities for all groups of society.

\section{REFERENCES}

1. Documentary samples of urban environment suitable-building for the disabled; translated by Eng. Rasoul Mir Hadi, Building and Housing Research Center- Tehran (1993).

2. Standards and regulations of urban development and architecture for the physicalmotor disabled. Building and Housing Research- Tehran (1999).

3. Afsah Hosseini, F.A. Office furniture and equipment suitable-building, the conference on suitabile-building of urban environmentTehran (2006)
4. Eghbal, R. Suitable-building of urban environments by emphasizing on sidewalk productivity. The conference on urban environment suitable-building. Tehran (2006)

5. Emakchi, Hamideh. Urban planning for the disabled. Master's Dissertation in Urban Planning- Advisor: Dr. Hossein Bahraini, Campus of Fine Arts- University of Tehran (1989)

6. Tajeddini, L, Mousavi, SH.A. Suitable-building of life environment for the physical-motor 
disabled- the Conference on Suitable-building of Urban Environment- Tehran (2006)

7. Johnson, B, M (Designing suitable passageways for the motor disabled, Translated by Forouz Roshan Bin, Building and Housing Research Center, Tehran

8. United Nations. The By-law of Equality of Opportunities for the disabled, Translated by Mehdi Babaee (1994)

9. United Nations. Preciseness in Design (Guide for making urban spaces and building suitable for the disabled), translated by Mehdi Babaee Ahari, Tehran Technical Advising and Engineering Organization, Tehran (1994)

10. Iran's Statistical Yearbook. Journals of Iran's Statistical Yearbook, Tehran (2007)

11. Saeed Nia, A. Design of spaces and urban furniture, Published by National Organization of Municipalities and Rural Governor's Offices, Tehran (2004)

12. Sharif Mohseni, Hooman. Fundamental planning for the disabled; Master's Dissertation in Architecture. Advisor: Dr. Golabchi, College of Fine Arts of Tehran University (1993)

13. Ghaem, Gisoo. Educational Buildings and the Disabled - Building and Housing Research Center- Tehran (1991)

14. Nozari, Shole. Fundamentals for Open Space Design of Residential Neighborhoods appropriate for the aged, Building and Housing Research Center- Tehran (2003)

15. Nik Ravan Mofrad, Mojgan. Modular Arrangement in Design and Building Construction System- Evaluation of Dimensions and Standards in design and construction- Building and Housing Research
Center- Tehran (1995)

16. Ministry of Interior- Technical Office. Case analysis of performance of architecture and urban planning regulations and standards for the disabled- Tehran (1994)

17. Allahverdi, Zavareh, M. Suitable-building for the physical disabled from the beginning up to now, challenges and solutions, specialized workshop of accessible public spaces for the physical disabled- Tehran (2004)

18. Knudson, P., creating a more accessible and equitable environment, Web Site: Hills Therapy Services, Australia Studies (1999).

19. Marcus, C., Francis, C., Propel places, Design Guideline for urban open space, New York (1990).

20. Miller, E., Chen, R., Noreen, M., Karnes, P., Willing to Engaged in Personal Relationships With Persons With Disabilities, University of Texas-Pan American, Journal Rehabilitation Counseling Bulletin, 52(4); (2009).

21. Pushkarev, B.S., Zupon, J. M., Urban space for pedestrian,Cambridge, Mass, Mitpress (1975).

22. Sanderson, M., Examination of Planning for Persons with Disabilities in Mid-size Canadian Municipalities, A thesis presented to the University ofWaterloo in fulfillment of the thesis requirement for the degree of Master of Arts,University of Waterloo Canada (2006).

23. Stevens, C., Living with Disability in Japan, Taylor \& Francis, Edition/Format: Article: EN, Japanese Studies, number 3 (2007).

24. www.un.org/socdev/enable/designm

25. www.independentliving.org

26. www.disebledunited.com 